\title{
Morphology and possible origins of the Perm anomaly in the lowermost mantle of Earth
}

\author{
YuMei He ${ }^{1,2 *}$, LianXing Wen ${ }^{3,4}$, and Yann Capdeville ${ }^{5}$ \\ ${ }^{1}$ Key Laboratory of Earth and Planetary Physics, Institute of Geology and Geophysics, Chinese Academy of Sciences, Beijing 100029, China; \\ ${ }^{2}$ Mohe Observatory of Geophysics, Institute of Geology and Geophysics, Chinese Academy of Sciences, Beijing 100029, China; \\ 'Laboratory of Seismology and Physics of Earth's Interior; School of Earth and Space Sciences, University of Science and Technology of China, Hefei 230026, \\ China; \\ ${ }^{4}$ Department of Geosciences, State University of New York at Stony Brook, Stony Brook, New York, USA; \\ ${ }^{5}$ Laboratoire de Planétologie et Géodynamique de Nantes, UMR6112, CNRS, Université de Nantes, Nantes, France \\ Key Points: \\ - The detailed morphology and velocity structure of the Perm anomaly near the core-mantle boundary of Earth is reassessed. \\ - Travel-time analysis and three-dimensional forward waveform modeling suggest that the anomaly is dome-shaped with a maximum \\ velocity reduction of $-3.5 \%$ at the core-mantle boundary. \\ - This anomaly may represent a stable small-scale chemical pile in the lowermost mantle.
}

Citation: He, Y. M., Wen, L. X. and Capdeville, Y. (2021). Morphology and possible origins of the Perm anomaly in the lowermost mantle of Earth. Earth Planet. Phys., 5(1), 105-116. http://doi.org/10.26464/epp2021009

\begin{abstract}
We have constrained a small-scale, dome-shaped low-velocity structure near the core-mantle boundary (CMB) of Earth beneath Perm (the Perm anomaly) using travel-time analysis and three-dimensional (3-D) forward waveform modeling of seismic data sampling of the mantle. The best-fitting dome-shaped model centers at $60.0^{\circ} \mathrm{E}, 50.5^{\circ} \mathrm{N}$, and has a height of $400 \mathrm{~km}$ and a radius that increases from $200 \mathrm{~km}$ at the top to $450 \mathrm{~km}$ at the CMB. Its velocity reduction varies from $0 \%$ at the top to $-3.0 \%$ at $240 \mathrm{~km}$ above the CMB to $-3.5 \%$ at the CMB. A surrounding 240-km-thick high-velocity D" structure has also been detected. The Perm anomaly may represent a stable smallscale chemical pile in the lowermost mantle, although the hypothesis of a developing mantle plume cannot be ruled out.
\end{abstract}

Keywords: seismic velocity structure; core-mantle boundary; Perm anomaly; chemical pile

\section{Introduction}

Seismic tomography and high-resolution waveform and traveltime analyses have revealed various low-velocity anomalies at the base of Earth's mantle, including two large-scale low-shear-velocity provinces (thousands of kilometers across) beneath the south-central Pacific Ocean and Africa (the Pacific Anomaly and African Anomaly, respectively), several small-scale (hundreds of kilometers across) anomalies beneath Perm, Iceland and Kamchatka (the Perm, Iceland and Kamchatka anomalies, respectively), and patches of ultra-low-velocity zones (with lateral scales of hundreds to tens of kilometers across) (Montelli et al., 2006; Wang Y and Wen LX, 2007; Ritsema et al., 2010; Simmon et al., 2010; Lay and Garnero, 2011; Lekic et al., 2012; Sun DY and Miller, 2013; Thorne et al., 2013; He YM et al., 2014, 2015; French and Romanowicz, 2015; Zhao CP et al., 2017; Yu SL and Garnero, 2018; Kim et al., 2020). Geodynamic studies have further indicated that the morphologies of the large- and small-scale anomalies place a

Correspondence to: Y. M. He, ymhe@mail.igcas.ac.cn

Received 14 JUL 2020; Accepted 15 NOV 2020.

Accepted article online 09 DEC 2020.

C 2021 by Earth and Planetary Physics. crucial constraint on their origins and dynamic processes (McNamara, 2019). Seismic studies of the African Anomaly and northeastern Pacific Anomaly have revealed a bell-shaped structure with sloped sides that is expected to be stable and long-lived (McNamara and Zhong SJ, 2004; Wang Y and Wen LX, 2007; Zhao CP et al., 2015). The northwestern Pacific Anomaly has a box-shaped structure with nearly vertical sides, implying that it is a metastable structure (Tan E and Gurnis, 2005; He YM and Wen LX, 2009). Both the Iceland and Kamchatka anomalies have mushroom-shaped or wide-cap-and-narrow-stem features, which fit the typical morphology, in theoretical and experimental modeling, of an unstable mantle plume (Griffiths and Campbell, 1990; He YM et al., 2014, 2015).

In 2012, Lekic et al. using the forward waveform modeling method, detected a localized low-velocity structure near the coremantle boundary (CMB) beneath Perm (the Perm anomaly) (Lekic et al., 2012). Their simplified model includes a 370-km-thick and 900-km-wide (at the CMB) cylinder with a velocity reduction of $-6 \%$ beneath Perm. However, the anomalous $S_{\text {diff }}$ phases of the event used in that study were recorded in the Taiwan province of China (Fig. 8 of Lekic et al., 2012); in the SKS phases of the same re- 
cords similar anomalous features have been observed and are therefore probably caused partly by the seismic heterogeneities in the receiver-side crust and upper mantle. The Perm anomaly, including its existence, geometry, and velocity structure, and its relationship with surrounding mantle, must be reassessed. Details regarding the structure of the Perm anomaly will help us understand its origin and dynamic process.

This study presents dense seismic observations that sample the lower mantle beneath Perm and show a systematic shift in arrival time and broadening of the $\mathrm{SH}$ and $\mathrm{SH}_{\text {diff }}$ waveforms with respect to the azimuth. Carefully selected seismic data and forward 3-D waveform modeling with a frequency range of up to $0.125 \mathrm{~Hz}$ enable us to reveal fine-scale structural features of the Perm anomaly. Our modeling suggests a dome-shaped low-shear-velocity anomaly with a maximum velocity reduction of $-3.5 \%$ at the $\mathrm{CMB}$ surrounded by a high-velocity $D$ " region near the CMB beneath Perm.

\section{Detection of the Morphology and Velocity Structure of the Perm Anomaly}

We first constrain the average shear-wave velocity near the CMB in the region of the Perm anomaly and the geographic extent of the Perm anomaly based on the differential travel-time residuals of ScS-S sampling the region. We then deduce the morphology and detailed velocity structure of the anomaly in the lowermost mantle based on waveform modeling $S, S_{\text {diff }}$ waves that cross the anomaly.

\subsection{Velocity Structure in the Lowermost Mantle Beneath Perm Based on Travel-time Analysis}

The geographic extent of the anomaly near the CMB is constrained by using $\mathrm{ScSH}-\mathrm{SH}$ differential travel-time residuals. Only ScS-S pairs with epicentral distances ranging from $45^{\circ}$ and $85^{\circ}$ and their SCS bouncing points at the CMB located between $20^{\circ} \mathrm{N}$ and $75^{\circ} \mathrm{N}$ and between $10^{\circ} \mathrm{E}$ and $130^{\circ} \mathrm{E}$ are examined. By measuring the difference in the peak-to-peak times of the $\mathrm{S}$ and ScS phases on the seismograms, the SCS-S differential travel-time residuals are obtained. A Butterworth filter with corner frequencies of 0.008 and $1 \mathrm{~Hz}$ has been applied to all seismograms. Finally 25 earthquakes with a total of $398 \mathrm{ScS}$-S travel-time data points are collected (Table S1 in the Supporting Information). The seismic data show good sampling coverage in the study area (Figure 1a). Travel-time contributions of the mantle structure at $500 \mathrm{~km}$ or more above the CMB are ruled out by using the mantle tomography model GyPSuMS (Simmons et al., 2010), following the same procedures outlined in He YM et al. (2015) (Table S2 in the Supporting Information). Thus, lateral velocity variations in the lowermost $500 \mathrm{~km}$ of the mantle are attributed mostly to the corrected ScS-S differential travel times, and the average shear-velocity in that depth range is inferred. The inferred shear velocity perturbations exhibit an approximately circular low-velocity area with a radius of approximately $450 \mathrm{~km}$ beneath Perm, surrounded by neutral or high-velocity anomalies (Figure 1b). The inferred velocity variations are similar to those obtained in past studies based on tomographic imaging and waveform analysis (Simmons et al., 2010; Ritsema et al., 2011; Lekic et al., 2012).

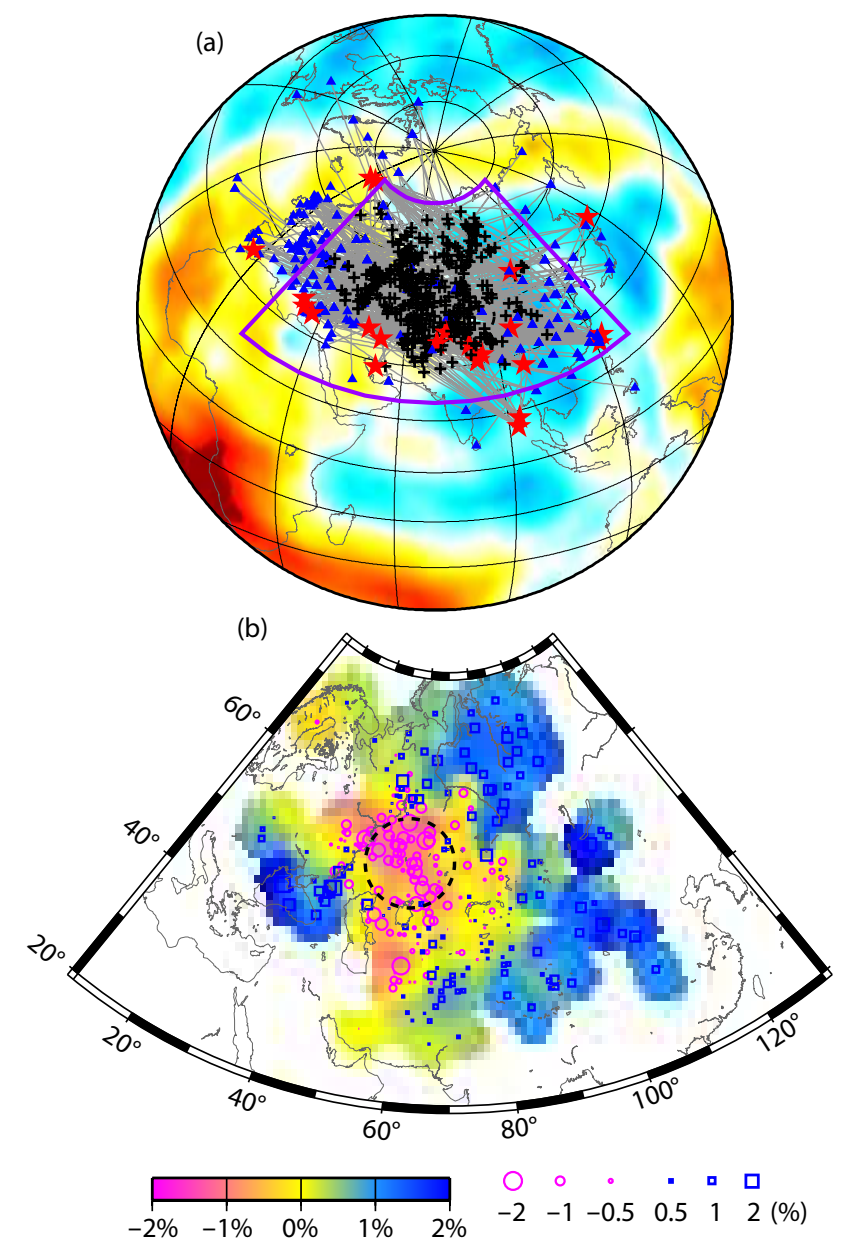

Figure 1. (a) Study region and ScS reflected points (black crosses) at the $\mathrm{CMB}$, along with earthquakes (red stars), seismic stations (deep blue triangles) and great-circle paths (gray lines) of the seismic phases used in this study. The background is shear-velocity perturbations at the CMB from the global shear-velocity tomographic model GyPSuMS (Simmons et al., 2010). (b) Average shear velocity perturbations in the bottom $500 \mathrm{~km}$ of the mantle inferred from the corrected ScS-S traveltime residuals. Blue squares and red circles represent velocity increases and decreases, respectively; their sizes are proportional to the magnitudes of the velocity perturbations. The boundary between low velocities and neutral or high velocities is approximated by the dashed circle. The shear velocity perturbations that are averaged over $1^{\circ} \times 1^{\circ}$ grids with a Gaussian cap with a radius of $2^{\circ}$ are shown as the background.

\subsection{Morphology and Velocity Structure of the Perm Anomaly Based on Waveform Modeling}

We construct a 3D model of the Perm anomaly based on the average velocity structure revealed by the ScS-S differential traveltime residuals and waveform modeling of the $S, S_{\text {diff }}$ waves that sample across the anomaly. The $S, S_{\text {diff }}$ waveforms have been proven to be highly sensitive to the geometric features of the seismic anomalies (Wen LX, 2002; Wang Y and Wen LX, 2004; To et al., 2005; He YM and Wen LX, 2009; Sun DY et al., 2009; Sun DY and Miller, 2013; Yuan and Romanowicz, 2017). For waveform modeling, we search for broadband tangential displacements of the $S$, $S_{\text {diff }}$ phases ranging from $90^{\circ}$ to $110^{\circ}$ for all possible events that 

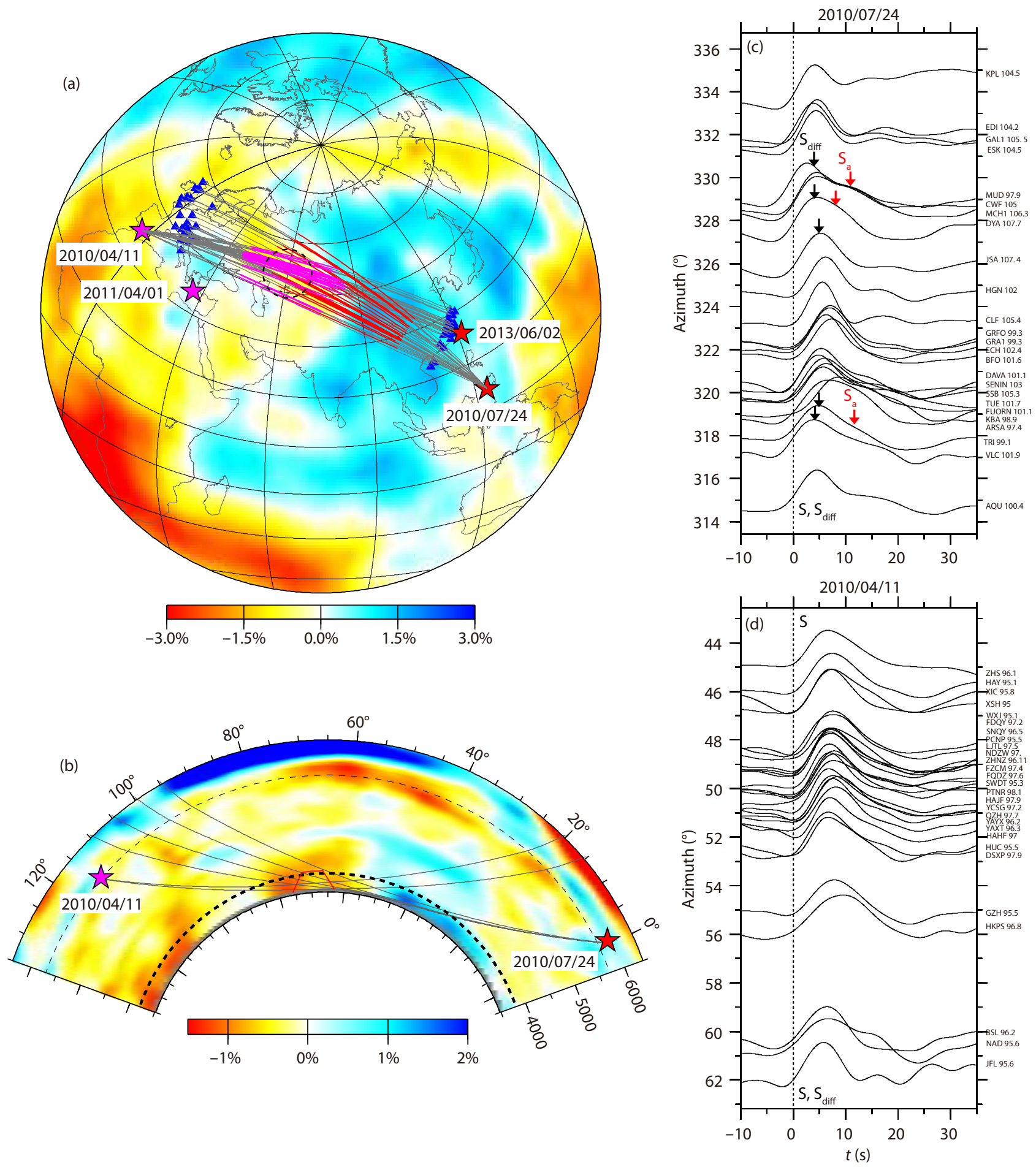

Figure 2. (a) Events 2010/04/11 and 2010/07/24 used for the waveform study (purple and red stars), S, $S_{\text {diff }}$ raypaths propagating in the lowermost $200 \mathrm{~km}$ of the mantle (purple and red bold lines), seismic stations (blue triangles) and great-circle paths (gray lines), along with reference earthquakes 2011/04/01 and 2013/06/02 (purple and red stars), the boundary of the anomaly (dashed circle) constrained by travel-time analysis (see Figure 1), and shear velocity perturbations at the CMB from Simmons et al. (2010) as a background. (b) Two-dimensional cross section of the global tomographic model GyPSuMS (Simmons et al., 2010) along the great circle path in (a), earthquakes (red and purple stars), raypath of $S, S_{\text {diff }}$ phases of event $2010 / 07 / 24$ at epicentral distances from $95^{\circ}$ to $110^{\circ}$ (gray lines), and raypath of $S, S_{\text {diff }}$ phases of event $2010 / 04 / 11$ at epicentral distances from $95^{\circ}$ to $100^{\circ}$ (gray lines). The geometry and location of the anomaly are shown by the bold red line (see Figure 3). (c, d) Observed tangential displacements as a function of azimuth for event 2010/07/24 (c) and event 2010/04/11 (d), aligned along the theoretical arrivals of the S, $S_{\text {diff }}$ phases based on the PREM (Dziewonski and Anderson, 1981) (dashed lines). The name and epicentral distance of each station are indicated on the right. The observed $\mathrm{S}, \mathrm{S}_{\text {diff }}$ and an additional phase (labeled as $\mathrm{S}_{\mathrm{a}}$ ) are indicated by black and red arrows in (c). 
sample the lowermost mantle beneath Perm and the surrounding area. All waveform data are bandpass-filtered from 0.008 to $0.125 \mathrm{~Hz}$. After visual inspection of all available data and exclusion of those with strong anisotropy effects in the upper mantle, we select the $S, S_{\text {diff }}$ data of two events for waveform modeling: one event (2010/07/24) occurred in the Philippines and was recorded in Europe, and the other (2010/04/11) occurred in Spain and was recorded in China (Figures 2 and S2 in the Supporting Information). Event 2010/04/11 was also used by Lekic et al. (2012) but mainly with different stations. Both events have simple sourcetime functions as well as high signal-to-noise ratios (Figures 2 and S1 and S2 in the Supporting Information). Seismic data from these two events provide good azimuthal sampling coverage of the Perm anomaly from opposite directions, with event 2010/07/24 at a distance range of $97^{\circ}-108^{\circ}$ and event $2010 / 04 / 11$ at a distance range of $95^{\circ}-98^{\circ}$ (Figures 2 and S1a and S2a in the Supporting Information).

The travel-time correction for the seismic data from events 2010/07/24 and 2010/04/11 consists of two procedures. We first re-determine the origin time and location of the chosen earthquakes based on $\mathrm{SH}, \mathrm{sSH}$ phases (Table 1). Then we perform travel-time corrections for the effect of seismic heterogeneities $500 \mathrm{~km}$ above the $\mathrm{CMB}$, based on the tomography model GyPSuMS (Simmons et al., 2010), and reference the corrections from seismic data for two events (2013/06/02 and 2011/04/01) that are closer to the seismic stations (Figures 2, S3 and S4 in the Supporting Information and Table 1). The corrected travel-time residuals are attributed to the Perm anomaly.

The waveform complexity and travel time of the $S, S_{\text {diff }}$ phases of event $2010 / 07 / 24$ vary significantly with the sampling azimuth from $314^{\circ}$ to $334^{\circ}$ (Figures 2c and S1 in the Supporting Information). In general, in the azimuthal range from $314^{\circ}$ to $323^{\circ}$ the widths of the apparent $S_{\text {diff }}$ phases gradually decrease and the travel-time delays increase, whereas in the azimuthal range from $323^{\circ}$ to $329^{\circ}$ the azimuth-dependent trend reverses, with the widths of the $S_{\text {diff }}$ phases increasing and the travel-time delays decreasing. The decrease in the widths of the $S_{\text {diff }}$ phases occurs $a b-$ ruptly in the azimuthal range from $332^{\circ}$ to $334^{\circ}$. The $S_{\text {diff }}$ phase arrives earlier than the theoretical arrivals calculated by the preliminary reference Earth model (PREM) (Dziewonski and Anderson, 1981 ) in the azimuthal ranges of $314^{\circ}$ to $320.5^{\circ}$ and $326^{\circ}$ to $334^{\circ}$. Most notably, an anomalous phase (labeled $\mathrm{S}_{\mathrm{a}}$ ) is observed after the $S_{\text {diff }}$ phase in the azimuthal range of $314^{\circ}$ to $321^{\circ}$, is absent in the middle azimuths up to $326^{\circ}$, re-appears in the azimuthal range of $327^{\circ}$ to $329^{\circ}$, and disappears again at large azimuths up to $334^{\circ}$ (Figure 2c). The anomalous phase exhibits the same polarity but a smaller amplitude relative to the direct $S_{\text {diff }}$ phase, with its separation from the direct $S_{\text {diff }}$ phase varying from approximately $9.0 \mathrm{~s}$ at $314^{\circ}$ to $7.0 \mathrm{~s}$ at $321^{\circ}$ and from $3.5 \mathrm{~s}$ at $327^{\circ}$ to $7.0 \mathrm{~s}$ at $329^{\circ}$.

Azimuth-dependent waveform variation is also observed in the $S$, $S_{\text {diff }}$ waveforms of event 2010/04/11 in the azimuthal range from $45^{\circ}$ to $62^{\circ}$ (Figures 2 and S2 in the Supporting Information). Although no clear anomalous phase is observed after the $S_{\text {diff }}$ phase, as it is for event $2010 / 07 / 24$ - likely due in that case to the shorter distance ranges $\left(95^{\circ}-98^{\circ}\right)$ and narrower azimuthal coverage of the data sampling, the observed waveform and travel-time features are similar to those in the seismic data of event 2010/07/24. In the azimuthal range of $45^{\circ}$ to $51^{\circ}$ the widths of the apparent $S_{\text {diff }}$ phases decrease gradually and the travel-time delays increase slightly, whereas in the azimuthal range from $51^{\circ}$ to $62^{\circ}$ the widths of the $S_{\text {diff }}$ phases increase and the travel-time delays decrease.

The azimuth-dependent waveform variations in events 2010/07/24 and 2010/04/11 are likely to be attributable to seismic heterogeneities near the CMB beneath Perm. Complexities in the source time functions, earthquake mislocations, or source-side mantle heterogeneities would produce similar waveform features and identical travel-time shifts to the stations, different from the observations. Receiver-side crust and upper mantle structures beneath Europe and China are also unable to account for such variations, because the seismic waveforms recorded at the same stations for one earthquake (event 2013/06/02) occurring in Taiwan of China (compared with event 2010/07/24), or event 2011/04/01 occurring in Greece (compared with event 2010/04/11), show simple and similar features, as well as the SKS phases of the same events (2010/07/24 and 2010/04/11) (Figures 2 and S3 and S4 in the Supporting Information).

We constructed 3D testing models based on the seismic structure revealed by the ScS-S differential travel-time residuals (Figure 1) and searched for the best-fitting models from the waveform modeling of the S, $S_{\text {diff }}$ data for events 2010/07/24 and 2010/04/11 (Figure 2). The travel-time data show a circular area of low velocities with a radius of $\sim 450 \mathrm{~km}$ surrounded by normal- or high-velocity anomalies near the CMB beneath Perm (Figure $1 \mathrm{~b}$ ). The waveform variations of events 2010/07/24 and 2010/04/11 suggest that the Perm anomaly is symmetrical north to south. We then set up a series of 3D models composed of a small-scale low-velocity anomaly and a surrounding high-velocity D" layer near the CMB beneath Perm (Figure 3). We tested the models with various lowvelocity anomaly geometries, including mushroom-shaped, cylindrical, dome-shaped and conical, with different heights, sizes, and velocity structures. The lateral extents of the low-velocity an-

Table 1. Events list.

\begin{tabular}{cccccc}
\hline Event & Origin time & Latitude $\left({ }^{\circ} \mathrm{N}\right)$ & Longitude $\left({ }^{\circ} \mathrm{E}\right)$ & Depth $(\mathrm{km})$ & Time Correction $(\mathrm{s})$ \\
\hline $2010 / 04 / 11$ & 2010.101 .22 .08 .12 & $37.07(37.07)$ & $-3.54(-3.64)$ & $620(618)$ & -1.5 \\
$2010 / 07 / 24$ & 2010.205 .05 .35 .01 & $6.17(6.17)$ & $123.56(123.46)$ & $545(540)$ & -2.5 \\
${ }^{*} 2011 / 04 / 01$ & 2011.091 .13 .29 .10 & $35.73(35.73)$ & $26.55(26.45)$ & $76(69)$ & -2.5 \\
${ }^{*} 2013 / 06 / 02$ & 2013.153 .05 .43 .03 & $23.7923 .79)$ & $121.14(121.24)$ & $17(17)$ & 0.5 \\
\hline
\end{tabular}

Values in parentheses are relocated latitude, longitude and depth. ${ }^{\star}$ Reference events. 
omaly are limited by the size of the circular area revealed by the travel-time analysis at the $\mathrm{CMB}$ and the sampling paths of the $\mathrm{S}$, $S_{\text {diff }}$ raypaths of event $2010 / 07 / 24$. The velocity reduction of the low-velocity anomaly was analyzed from $-6 \%$ to $0 \%$ and the velocity jump of the surrounding high-velocity D" layer was analyzed from $3.5 \%$ to $0 \%$, based on the results of previous studies (Wyses- sion et al., 1998; Lekic et al., 2012; He YM et al., 2014, 2015). A coupled normal mode/spectral element method was applied to calculate the 3-D synthetic waveforms (Capdeville et al., 2003).

The preferred models have a lowermost portion with a radius of $450 \mathrm{~km}$ and velocity reductions from $-3 \%$ at $240 \mathrm{~km}$ above the $\mathrm{CMB}$ to $-3.5 \%$ at the $\mathrm{CMB}$. Models with a larger velocity decrease
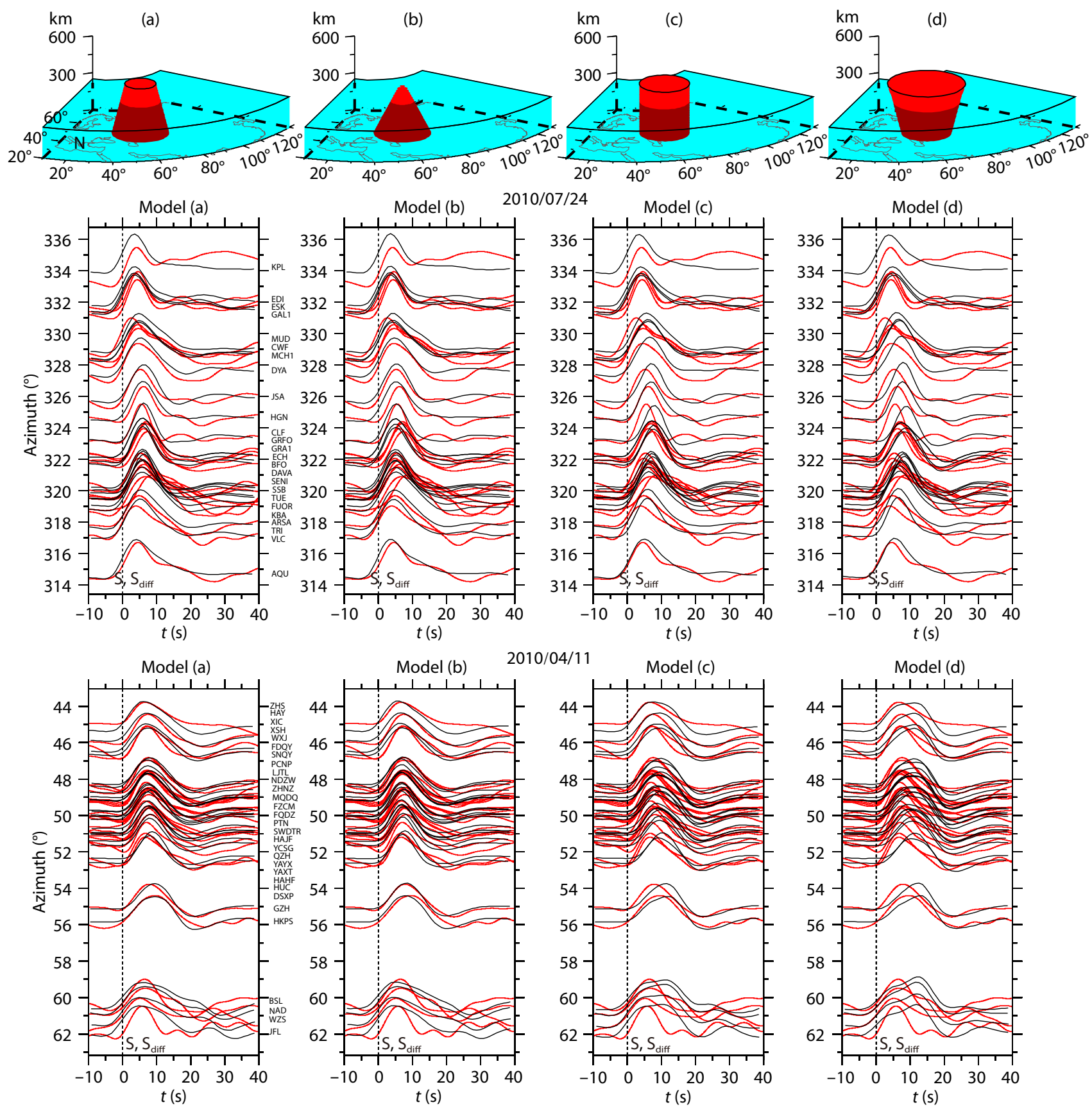

Figure 3. Examples of four types of tested models (top panels) and comparisons between seismic observations and modeled synthetics for events 2010/07/24 (middle panels) and 2010/04/11 (bottom panels). Top panels: all models have a low-velocity structure with a total thickness of $400 \mathrm{~km}$ (red region) surrounded by a 240-km-thick high-velocity structure (light blue region) but with the various shapes for the low-velocity structure: (a) preferred dome-shaped model, with the radius gradually changing from $200 \mathrm{~km}$ at the top to $450 \mathrm{~km}$ at the CMB; (b) conical model with a radius of $450 \mathrm{~km}$ at the $\mathrm{CMB}$; (c) cylindrical model, with a radius of $450 \mathrm{~km}$, and (d) mushroom-shaped model, with the radius changing gradually from $600 \mathrm{~km}$ at the top to $450 \mathrm{~km}$ at the CMB. Middle and bottom panels: synthetics from left to right are calculated based on the seismic models from left to right in the top panels. The observed tangential displacements are plotted in red and the synthetics in black. Both the synthetics and data are aligned along the PREM predictions. 
(for example, from $-4 \%$ at $240 \mathrm{~km}$ to $-6 \%$ at the $\mathrm{CMB}$ ) generate large amplitudes in the secondary phase at stations BSL, NAD, WZS, and JFL that do not match the observed waveforms of event 2010/04/11. The preferred models also have an upper portion with a lateral dimension that is smaller than that of the lowermost portion. Models with an upper portion radius of less than $200 \mathrm{~km}$ generate azimuthal dependence values and amplitudes that are similar to those of the secondary phase observed in the data (Figure 3, middle and bottom panels, models (a) and (b)). In these versions of the model, the direct $S, S_{\text {diff }}$ phase is generated by the seismic structure outside the low-velocity anomaly, whereas the secondary phase is generated by the low-velocity anomaly. Models with an upper portion radius greater than or equal to that of the bottom portion generate a strong secondary phase at every sampled azimuth for event 2010/04/11, a feature that does not match the observed $\mathrm{S}$ and $\mathrm{S}_{\text {diff }}$ (Figure 3, bottom panel, models (c) and (d)). These models also generate much delayed $S$ and $S_{\text {diff }}$ phases for event 2010/07/24 that do not match the observations (Figure 3, middle panel, models (c) and (d)). Among the models, we thus choose the dome-shaped model as the preferred model because the synthetics produced by this model fit the observations slightly better that those of the conical model. The synthetic tests indicate that models with a thickness of $350-450 \mathrm{~km}$ can produce synthetics that fit the observations. The high-velocity region surrounding the low-velocity anomaly is necessary to explain the faster $S_{\text {diff }}$ phases in the azimuthal ranges of $314^{\circ}$ to $320.5^{\circ}$ and $326^{\circ}$ to $334^{\circ}$ for event $2010 / 07 / 24$ and the ScS-S differential travel-time residuals (Figures 1 and $2 \mathrm{c}$ ). The high-velocity structure also broadens the waveforms of the seismic phases sampling the border of the anomaly and narrows the waveforms of the seismic phases sampling the center of the anomaly.

The best-fitting model is a dome-shaped low-velocity anomaly located at $60.0^{\circ} \mathrm{E}, 50.5^{\circ} \mathrm{N}$, with a height of $400 \mathrm{~km}$ and a radius that increases from $200 \mathrm{~km}$ at the top to $450 \mathrm{~km}$ at the CMB (model (a) in Figure 3). Its velocity structure decreases from $0 \%$ at the top to $-3.0 \%$ at $240 \mathrm{~km}$ and to $-3.5 \%$ at the CMB. The high-velocity region surrounding the low-velocity anomaly has a velocity jump of $3.0 \%$ at $240 \mathrm{~km}$ above the CMB following by a negative gradient from $3.0 \%$ to $1.0 \%$ at the $\mathrm{CMB}$.

\section{Discussion}

\subsection{Differences From Previous Analysis of the Perm \\ Anomaly}

The Perm anomaly was first reported by Lekic et al. (2012). Their study suggested a 370-km-thick and 900-km-wide cylindrical lowvelocity anomaly centered at $54^{\circ} \mathrm{E}, 50^{\circ} \mathrm{N}$. Our best-fitting model has a similar thickness and width, but it has a dome-shaped lowvelocity anomaly located at $60.0^{\circ} \mathrm{E}, 50.5^{\circ} \mathrm{N}$ surrounded by a $240-$ $\mathrm{km}$-thick high-velocity province. The low-velocity structure in our model decreases from $0 \%$ at the top to $-3.5 \%$ at the $C M B$, which is much smaller than the previous average velocity reduction result of $-6 \%$ (Lekic et al., 2012). The model by Lekic et al. was derived based on waveform modeling of $S, S_{\text {diff }}$ phases from event 2010/04/11, which were mainly recorded in Japan and the Taiwan province of China, whereas our best-fitting model was derived from ScS-S travel-time analysis and waveform modeling of $S, S_{\text {diff }}$ phases from events 2010/04/11 and 2010/07/24. In this study, we opt not to use the seismic data of event 2010/04/11 recorded in Taiwan of China because both the $S_{\text {diff }}$ and SKS phases of the event show similar anomalously large travel-time delays and amplitudes. Moreover, the records at the same stations for the reference event 2011/04/01 occurring in Greece show similar data features (Figure 2a). It is difficult to rule out the possibility that the observed anomalous features of the seismic data of event 2010/04/11 in Lekic et al. (2012) are contributed to in part by receiver-side crust and upper mantle structures. Instead, we use seismic data recorded in southern China and data reorded in Europe from another event, 2010/07/24, occurring in Mindanao, Philippines. The seismic data recorded in southern China, though with similar sampling azimuths as the data recorded in Taiwan of China, have much smaller travel-time delays, implying a smaller velocity reduction associated with the anomaly. In comparison with previous reports, the dense ScS-S travel-time data used in this study allow the geographic extent of the low-velocity region to be better constrained. The detailed waveform features of the seismic data from events 2010/04/11 and 2010/07/24 — in particular, those of the additional event 2010/07/24 used in this study, allow the morphology and velocity structure of the anomaly to be tightly constrained. Furthermore, our systematic tests of 3-D models based on 3-D forward waveform modeling of the seismic observations with frequency contents of up to $0.125 \mathrm{~Hz}$ have enabled us to identify the best-fitting shape of the low-velocity anomaly and the existence of a surrounding high-velocity province.

\subsection{Possible Interpretation and Dynamic Consequences of the Perm Anomaly Relative to Other Localized Anomalies in the Lowermost Mantle}

Seismic studies have now revealed several low-velocity anomalies near the CMB that extend at least several hundred kilometers above the D" layer, with various lateral scales and geometric features (Wang Y and Wen LX, 2004, 2007; To et al., 2005; He YM and Wen LX, 2009, 2012; Lekic et al., 2012; Sun DY and Miller, 2013; He YM et al., 2015; Zhao CP et al., 2015; French and Romanowicz, 2015). At the regional scale, the African and Pacific Anomalies occupy, respectively, areas of approximately $1.8 \times 10^{7} \mathrm{~km}^{2}$ and $1.9 \times 10^{7} \mathrm{~km}^{2}$ at the CMB. The African Anomaly exhibits a bell-like geometry in the mid-lower mantle extending $1,300 \mathrm{~km}$ above the CMB. In the lowermost $300 \mathrm{~km}$ of the mantle, the African Anomaly has sharp edges, rapidly varying thicknesses, and a strong shear velocity reduction varying from $-2 \%$ at the top to approximate of $-10 \%$ at the bottom. These features imply that the African Anomaly is both compositionally distinct and geologically stable (Wang Y and Wen LX, 2004, 2007). The Pacific Anomaly is composed of several piles and each pile has a velocity structure varying from $-3 \%$ (top) to $-5 \%$ (CMB). The northwestern pile has sharp sides in the lower mantle that extend at least $740 \mathrm{~km}$ above the $\mathrm{CMB}$, whereas the northern pile has sloped sides in the lower mantle that extend approximately $450 \mathrm{~km}$ above the CMB. These features imply a metastable thermo-chemical anomaly (northwestern pile) or a geologically stable chemical anomaly (northern pile) (He YM and Wen LX, 2009, 2012). At the local scale, three lowvelocity anomalies with lateral dimensions of several hundreds of kilometers at the CMB and surrounded by high-velocity struc- 

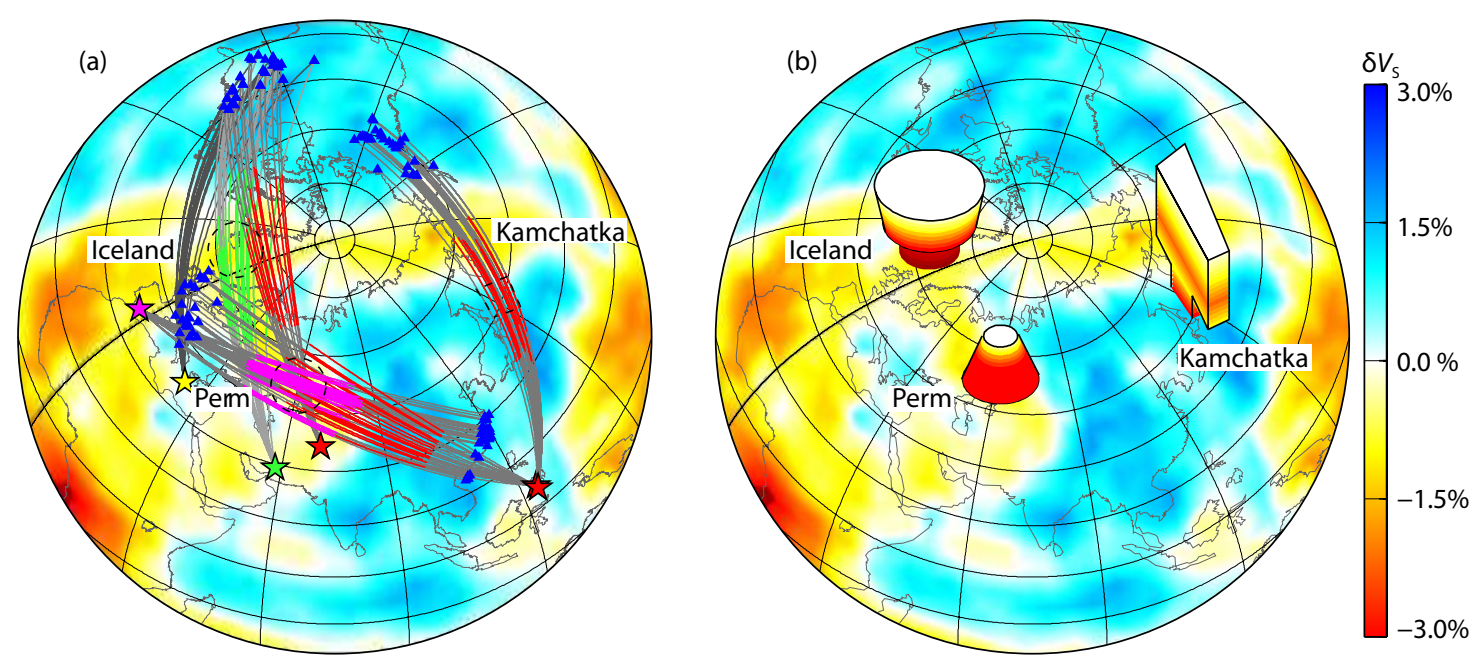

Figure 4. (a) Events used to constrain the geometric and velocity structures of the Iceland, Perm and Kamchatka anomalies in the lowermost

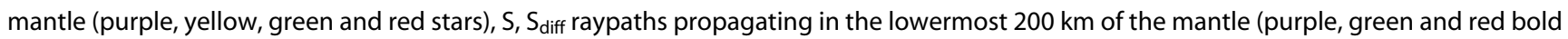
lines), seismic stations (deep blue triangles) and great-circle paths (gray lines). The boundaries of the anomalies at the CMB are indicated by dashed circles and rectangles. (b) Three-dimensional view of the constructed models for the three anomalies at the base of the mantle (2-D for Kamchatka anomaly and 3-D for Iceland and Perm anomalies). The best-fitting Iceland model is mushroom-shaped, with a stem with a radius of $350 \mathrm{~km}$ in the lowermost $250 \mathrm{~km}$ of the mantle and a cap with a radius that increases from $550 \mathrm{~km}$ at $250 \mathrm{~km}$ above the CMB to $650 \mathrm{~km}$ at $600 \mathrm{~km}$ above the CMB. The best-fitting Kamchatka model has a wide cap with a diameter of approximately $1600 \mathrm{~km}$ and a narrow stem with a diameter of approximately $550 \mathrm{~km}$. The detailed velocity structures of the constructed models are illustrated by different colors in accordance with the legend (e.g., red represents velocity reduction of $-3 \%$ and white represents velocity reduction of $0 \%$ ), except the colors of the stem of the Iceland model range from red (a velocity reduction of $-3 \%$ at $240 \mathrm{~km}$ above the $\mathrm{CMB}$ ) to brown (a velocity reduction of $-6 \%$ at the CMB). The backgrounds in (a) and (b) are tomographic shear velocity perturbations at the CMB from a tomographic model by Simmons et al. (2010).

tures are identified beneath Iceland, Kamchatka, and Perm (Lekic et al., 2012; He YM et al., 2014, 2015 and this study). The Iceland anomaly has a 600-km-thick mushroom-shaped structure with a velocity structure that decreases from $0 \%$ (top) to $-6 \%$ (CMB). The Kamchatka anomaly has an 800-km-thick narrow-stem-and-widecap structure with a velocity structure varying from $0 \%$ at the top to $-1.2 \%$ at $210 \mathrm{~km}$ above the CMB. The Perm anomaly has a $400-$ $\mathrm{km}$-thick dome-shaped structure with a velocity structure that decreases from 0\% (top) to 3.5\% (CMB) (Figure 4). The mushroomshaped (or narrow-stem-and-wide-cap) structure is a typical morphology of a mantle plume both in theoretical geodynamical modeling (Loper, 1991) and in laboratory experiments (Griffiths and Campbell, 1990), and the Iceland and Kamchatka anomalies may represent two mantle plumes in the lowermost mantle. The dome-shaped feature of the Perm anomaly is apparently different from the mushroom shape of the Iceland anomaly and the widecap-and-narrow-stem shape of the Kamchatka anomaly and may represent a different dynamic process. The geometric feature of the Perm anomaly is similar to the bell-shaped structure of the African Anomaly and may represent a stable chemical pile. However, unlike the regional-scale geometry of the African anomaly, which suggests a stable chemical pile, the local-scale domeshaped structure of the Perm anomaly can also be observed in a particular stage of a developing mantle plume (Farnetani and Samuel, 2005). Thus, the Perm anomaly may represent a stable small-scale chemical pile or a developing mantle plume generated through complex interactions with the surrounding high-velocity mantle.

Our results suggest that revealing the fine-scale morphology of low-velocity anomalies is extremely important for understanding their origins and dynamic processes. It is worthwhile to look further into worldwide high-velocity regions and the ambient mantle for waveform complexities at large distances from $90^{\circ}$ to $110^{\circ}$. Constructing the global framework of regional- and local-scale low-velocity anomalies and surrounding mantle will improve our understanding of the ambiguous dynamic processes in the lowermost mantle.

\section{Conclusion}

We have constrained the detailed morphology and velocity structure of the seismic anomaly near the CMB beneath Perm. Traveltime analysis and forward 3D waveform modeling studies suggest that the low-velocity anomaly beneath Perm is a domeshaped feature with a thickness of $400 \mathrm{~km}$ and a diameter varying from $400 \mathrm{~km}$ (top) to $900 \mathrm{~km}$ (CMB) and a surrounding 240-kmthick high-velocity D" structure. The dome-shaped geometry of the Perm anomaly is consistent with that of a stable chemical pile or of a developing mantle plume near the CMB.

\section{Acknowledgments}

Data were downloaded from the Incorporated Research Institutions for Seismology and Data Management Center of China National Seismic Network at Institute of Geophysics, China Earthquake Administration (Zheng XF et al., 2010). Figures were prepared using the General Mapping Tools (Wessel and Smith, 1995). We also thank Barbara Romanowicz and Vedran Lekic for their helpful discussions. This research was supported by the National Natural Science Foundation of China (grant 41474042), the Key 

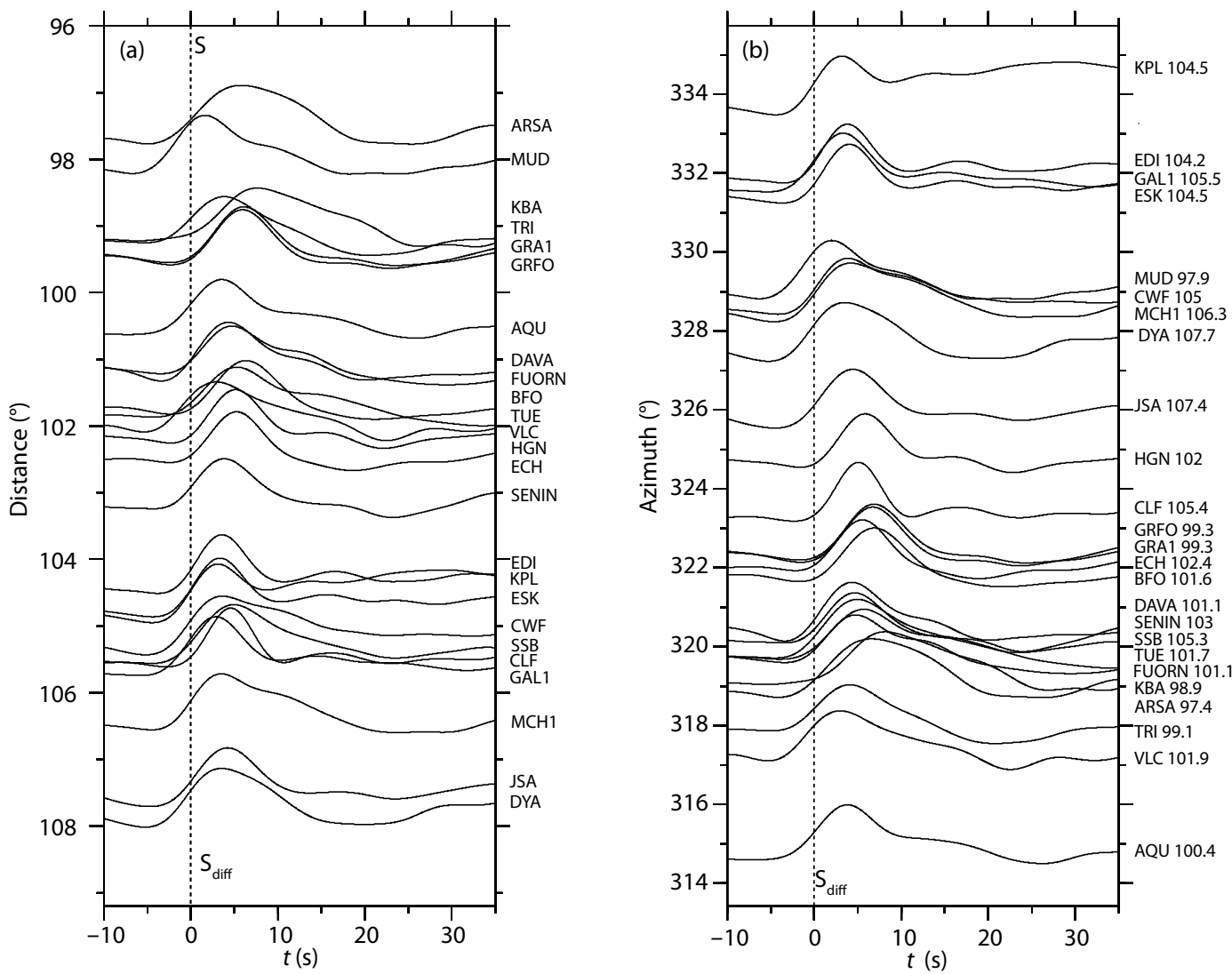

Figure S1. Tangential displacements for event 2010/07/24 in Mindanao, Philippines and recorded in Europe. Seismic waveforms are aligned along epicentral distance (a) or azimuth (b) and with the calculated $S, S_{\text {diff }}$ arrivals on the basis of PREM.
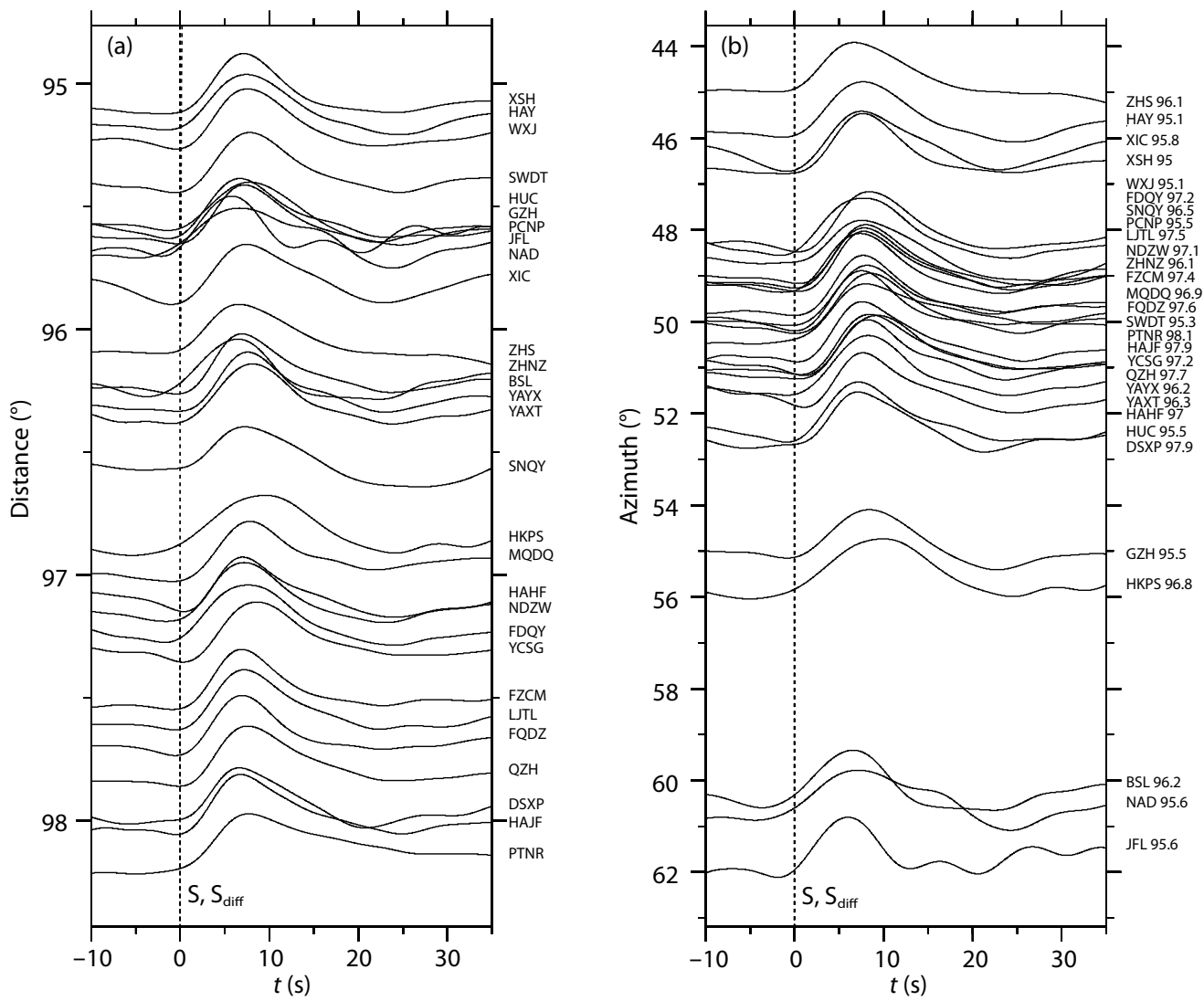

Figure S2. Tangential displacements for event 2010/04/11 in Greece and recorded in China. Seismic waveforms are aligned along epicetral distance (a) or azimuth (b) and with the calculated $\mathrm{S}, \mathrm{S}_{\text {diff }}$ arrivals on the basis of PREM. 

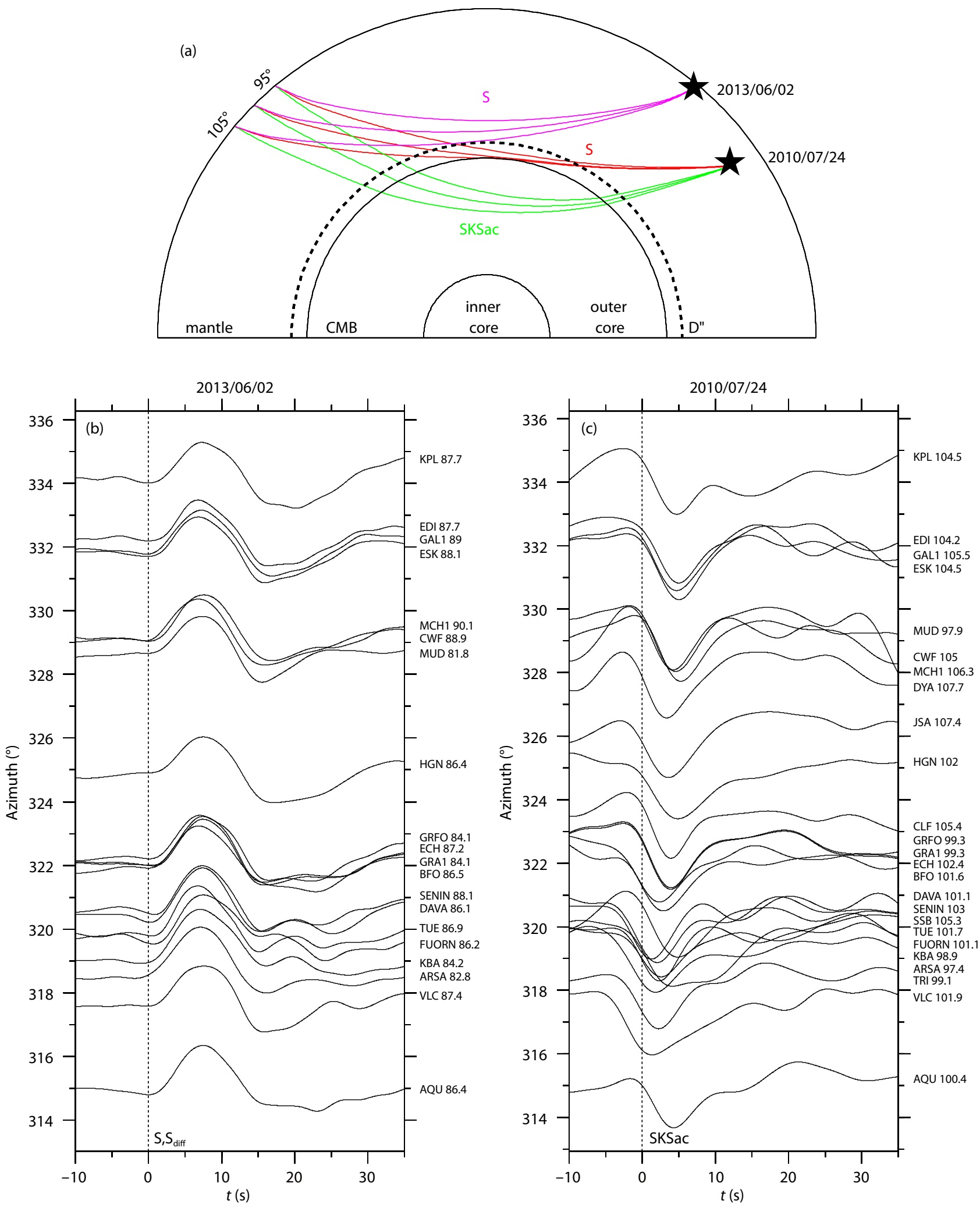

Figure S3. (a) Raypaths of direct $\mathrm{S}$ at eipcentral distances from $80^{\circ}$ to $90^{\circ}$ (purple lines) for event $2013 / 06 / 02$, and raypaths of direct $\mathrm{S}, \mathrm{S}_{\text {diff }}$ at epicentral distances from $95^{\circ}$ to $105^{\circ}$ (red lines), and SKS at epicentral distances from $95^{\circ}$ to $105^{\circ}$ (green lines) for event $2010 / 07 / 24$. These raypaths are calculated on the basis of PREM. (b) Tangential displacements for event 2013/06/02 in Taiwan of China and recorded in Europe. Seismic waveforms are aligned along the calculated SH arrivals on the basis of PREM. (c) Radial displacements for event 2010/07/24 in Mindanao, Philippines recorded in Europe. Seismic waveforms are aligned along the calculated SKSac arrivals on the basis of PREM. 

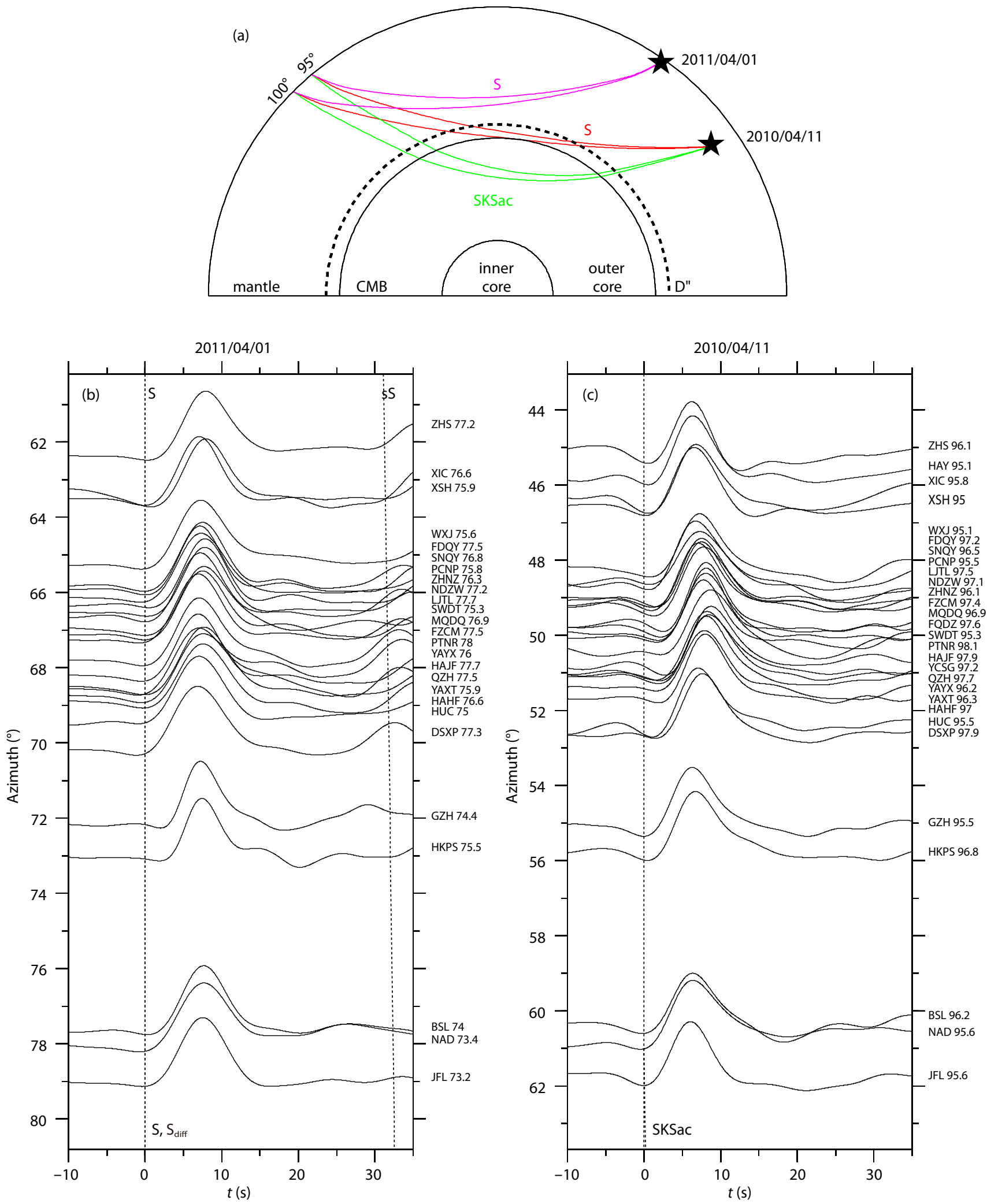

Figure S4. (a) Raypaths of direct $S$ at eipcentral distances from $75^{\circ}$ to $80^{\circ}$ (purple lines) for event 2011/04/01, and raypaths of direct $S, S_{\text {diff }}$ at epicentral distances from $95^{\circ}$ to $100^{\circ}$ (red lines), and SKS at epicentral distances from $95^{\circ}$ to $100^{\circ}$ (green lines) for event 2010/04/11. These raypaths are calculated on the basis of PREM. (b) Tangential displacements for event 2011/04/01 occurred in Greece and recorded in China. Seismic waveforms are aligned along the calculated SH arrivals on the basis of PREM. (c) Radial displacements for event 2010/04/11 occurred in Spain and recorded in China. Seismic waveforms are aligned along the calculated SKSac arrivals on the basis of PREM. 
Research Program of the Institute of Geology \& Geophysics, Chinese Academy of Sciences (IGGCAS), grant IGGCAS-201904, the Computer Simulation Lab, IGGCAS and NSF (grants 0911319 and 1214215).

\section{Auxiliary Material}

This data set contains seismic data for an event (2010/07/24) occurred in Mindanao, Philippines and a reference event (2013/06/02) occurred in Taiwan of China. Both events are recorded in Europe. Seismic data for another event (2010/04/11) occurred in Spain and relative reference event (2011/04/01) occurred in Greece are also presented. Tangential displacements along with epicentral distance or azimuth for events 2010/07/24 and 2010/04/11 are shown in the Figure S1 and Figure S2, respectively. Raypaths, tangential displacements for event 2013/06/02 and radial displacements for event 2010/07/24 are shown in the Figure S3. Figure S4 presents tangential displacements for event 2011/04/01 and radial displacements for event 2010/04/11. Events list for travel time analyses is shown in Tables S1, and correlation coefficients between S and ScS-S, and ScS and ScS-S are shown in Table S2.

Table S1. Events for travel time analysis.

\begin{tabular}{cccc}
\hline Origin time & Latitude $\left({ }^{\circ} \mathrm{N}\right)$ & Longitude $\left({ }^{\circ} \mathrm{E}\right)$ & Depth $(\mathrm{km})$ \\
\hline 2000.159 .21 .46 .55 & 26.86 & 97.24 & 33 \\
2002.022 .04 .53 .52 & 35.57 & 26.63 & 95 \\
2002.062 .12 .08 .20 & 36.50 & 70.48 & 226 \\
2002.256 .22 .28 .29 & 13.01 & 93.11 & 21 \\
2002.321 .04 .53 .55 & 47.78 & 145.99 & 484 \\
2003.107 .00 .48 .39 & 37.53 & 96.48 & 14 \\
2004.149 .12 .38 .43 & 36.25 & 51.62 & 17 \\
2004.289 .04 .08 .49 & 24.53 & 122.77 & 100 \\
2006.008 .11 .34 .56 & 36.31 & 23.21 & 66 \\
2006.091 .10 .02 .20 & 22.92 & 121.28 & 10 \\
2006.356 .19 .50 .46 & 10.70 & 92.40 & 31 \\
2007.093 .03 .35 .06 & 36.52 & 70.69 & 213 \\
2008.009 .08 .26 .45 & 32.29 & 85.17 & 10 \\
2008.080 .22 .32 .58 & 35.49 & 81.47 & 10 \\
2008.160 .12 .25 .30 & 37.96 & 21.53 & 16 \\
2008.238 .13 .21 .59 & 30.90 & 83.52 & 12 \\
2008.240 .01 .35 .32 & 51.61 & 104.16 & 16 \\
2008.269 .01 .47 .12 & 30.83 & 83.47 & 10 \\
2008.279 .15 .52 .49 & 39.53 & 73.82 & 27 \\
2009.232 .06 .35 .05 & 72.21 & 0.95 & 10 \\
2010.101 .22 .08 .11 & 37.01 & -3.48 & 620 \\
2011.091 .13 .29 .10 & 35.66 & 26.56 & 60 \\
2012.145 .22 .47 .46 & 72.96 & 5.68 & 10 \\
2012.224 .12 .23 .18 & 38.33 & 46.83 & 51.59 \\
\hline
\end{tabular}

Table S2. Correlation coefficients (CC).

\begin{tabular}{ccc}
\hline & CC between S and ScS-S & CC between ScS and ScS-S \\
\hline Raw data & -0.26 & 0.81 \\
GyPSuM & -0.23 & 0.85 \\
HMSL_S06 & -0.30 & 0.83 \\
S362ANI & -0.22 & 0.81 \\
S40RTS & -0.31 & 0.84 \\
SAW642ANB & -0.22 & 0.78 \\
TX2011 & -0.28 & 0.85 \\
\hline
\end{tabular}

\section{References}

Capdeville, Y., To, A., and Romanowicz, B. (2003). Coupling spectral elements and modes in a spherical Earth: an extension to the 'sandwich' case. Geophys. J. Int., 154(1), 44-57. https://doi.org/10.1046/j.1365246X.2003.01959.x

Dziewonski, A. M., and Anderson, D. L. (1981). Preliminary reference earth model. Phys. Earth Planet. Inter., 25(4), 297-356. https://doi.org/10.1016/0031-9201(81)90046-7

Farnetani, C. G., and Samuel, H. (2005). Beyond the thermal plume paradigm. Geophys. Res. Lett., 32(7), L07311. https://doi.org/10.1029/2005GL022360

French, S. W., and Romanowicz, B. (2015). Broad plumes rooted at the base of the Earth's mantle beneath major hotspots. Nature, 525(7567), 95-99. https://doi.org/10.1038/nature14876

Griffiths, R. W., and Campbell, I. H. (1990). Stirring and structure in mantle starting plumes. Earth Planet. Sci. Lett., 99(1-2), 66-78. https://doi.org/10.1016/0012-821X(90)90071-5

He, Y. M., and Wen, L. X. (2009). Structural features and shear-velocity structure of the "Pacific Anomaly". J. Geophys. Res., 114(B2), B02309. https://doi.org/10.1029/2008JB005814

He, Y. M., and Wen, L. X. (2012). Geographic boundary of the "Pacific Anomaly" and its geometry and transitional structure in the north. J. Geophys. Res., 117(B9), B09308. https://doi.org/10.1029/2012JB009436

He, Y. M., Wen, L. X., and Zheng, T. Y. (2014). Seismic evidence for an 850 km thick low-velocity structure in the Earth's lowermost mantle beneath Kamchatka. Geophys. Res. Lett., 41(20), 7073-7079. https://doi.org/10.1002/2014GL061249

He, Y. M., Wen, L. X., Capdeville, Y., and Zhao, L. (2015). Seismic evidence for an Iceland thermo-chemical plume in the Earth's lowermost mantle. Earth Planet. Sci. Lett., 417, 19-27. https://doi.org/10.1016/j.epsl.2015.02.028

Kim, D., Lekić, V., Ménard, B., Baron, D., and Taghizadeh-Popp, M. (2020). Sequencing seismograms: a panoptic view of scattering in the core-mantle boundary region. Science, 368(6496), 1223-1228. https://doi.org/10.1126/science.aba8972

Lay, T., and Garnero, E. J. (2011). Deep mantle seismic modeling and imaging. Annu. Rev. Earth Planet. Sci., 39, 91-123. https://doi.org/10.1146/annurevearth-040610-133354

Lekic, V., Cottaar, S., Dziewonski, A., and Romanowicz, B. (2012). Cluster analysis of global lower mantle tomography: A new class of structure and implications for chemical heterogeneity. Earth Planet. Sci. Lett., 357-358, 68-77. https://doi.org/10.1016/j.epsl.2012.09.014

Loper, D. E. (1991). Mantle plumes. Tectonophysics, 187(4), 373-384. https://doi.org/10.1016/0040-1951(91)90476-9

McNamara, A. K., and Zhong, S. J. (2004). Thermochemical structures within a spherical mantle: superplumes or piles?. Geophys. Res., 109(B7), B07402. https://doi.org/10.1029/2003JB002847

McNamara, A. K. (2019). A review of large low shear velocity provinces and ultra low velocity zones. Tectonophysics, 760, 199-220. https://doi.org/10.1016/j.tecto.2018.04.015

Montelli, R., Nolet, G., Dahlen, F. A., and Masters, G. (2006). A catalogue of deep mantle plumes: New results from finite-frequency tomography. Geochem. Geophys. Geosyst., 7(11), Q11007. https://doi.org/10.1029/2006GC001248 
Ritsema, J., Deuss, A., van Heijst, H. J., and Woodhouse, J. H. (2010). S40RTS: a degree-40 shear-velocity model for the mantle from new Rayleigh wave dispersion, teleseismic traveltime and normal-mode splitting function measurements. Geophys. J. Int., 184(3), 1223-1236. https://doi.org/10.1111/j.1365-246X.2010.04884.x

Simmons, N. A., Forte, A. M., Boschi, L., and Grand, S. P. (2010). GyPSuM: a joint tomographic model of mantle density and seismic wave speeds. J. Geophys. Res., 115(B12), B12310. https://doi.org/10.1029/2010JB007631

Sun, D. Y., Helmberger, D., Ni, S. D., and Bower, D. (2009). Direct measures of lateral velocity varation in the deep Earth. J. Geophys. Res., 114(B5), B05303. https://doi.org/10.1029/2008JB005873

Sun, D. Y., and Miller, M. S. (2013). Study of the western edge of the African large low shear velocity province. Geochem. Geophys. Geosyst., 14(8), 3109-3125. https://doi.org/10.1002/ggge.20185

Tan, E., and Gurnis, M. (2005). Metastable superplumes and mantle compressibility. Geophys. Res. Lett., 32(20), L20307. https://doi.org/10.1029/2005GL024190

Thorne, M. S., Garnero, E. J., Jahnke, G., Igel, H., and McNamara, A. K. (2013). Mega ultra low velocity zone and mantle flow. Earth Planet. Sci. Lett., 364 , 59-67. https://doi.org/10.1016/j.epsl.2012.12.034

To, A., Romanowicz, B., Capdeville, Y., and Takeuchi, N. (2005). 3D effects of sharp boundaries at the borders of the African and Pacific Superplumes: observation and modeling. Earth Planet. Sci. Lett., 233(1-2), 137-153. https://doi.org/10.1016/j.epsl.2005.01.037

Wang, Y., and Wen, L. X. (2004). Mapping the geometry and geographic distribution of a very low velocity province at the base of the Earth's mantle. J. Geophys. Res., 109(B10), B10305. https://doi.org/10.1029/2003JB002674

Wang, Y., and Wen, L. X. (2007). Geometry and P and S velocity structure of the "African Anomaly". J. Geophys. Res., 112(B5), B05313.
https://doi.org/10.1029/2006JB004483

Wen, L. X. (2002). An SH hybrid method and shear velocity structures in the lowermost mantle beneath the central Pacific and south Atlantic oceans. J. Geophys. Res., 107(B3), 2055. https://doi.org/10.1029/2001JB000499

Wessel, P., and Smith, W. H. F. (1995). New version of the Generic Mapping Tools released. Eos Trans. Am. Geophys. Union, 76(47), 329.

Wysession, M. E., Lay, T., Revenaugh, J., Williams, Q., Garnero, E. J., Jeanloz, R., and Kellogg, L. H. (1998). The D" discontinuity and its implications. In M. Gurnis, et al. (Eds.), The Core-Mantle Boundary Region (pp. 273-298), Washington, DC: AGU. https://doi.org/10.1029/GD028p0273

Yu, S. L., and Garnero, E. J. (2018). Ultra-low velocity zone locations: a global assessment. Geochem., Geophys., Geosyst., 19(2), 396-414. https://doi.org/10.1002/2017GC007281

Yuan, K. Q., and Romanowicz, B. (2017). Seismic evidence for partial melting at the root of major hot spot plumes. Science, 357(6349), 393-397. https://doi.org/10.1126/science.aan0760

Zhao, C. P., Garnero, E. J., McNamara, A. K., Schmerr, N., and Carlson, R. W. (2015). Seismic evidence for a chemically distinct thermochemical reservoir in Earth's deep mantle beneath Hawaii. Earth Planet. Sci. Lett., 426, 143-153. https://doi.org/10.1016/j.epsl.2015.06.012

Zhao, C. P., Garnero, E. J., Li, M. M., McNamara, A., and Yu, S. L. (2017). Intermittent and lateral varying ULVZ structure at the northeastern margin of the Pacific LLSVP. J. Geophys. Res. Solid Earth, 122(2), 1198-1220. https://doi.org/10.1002/2016JB013449

Zheng, X. F., Yao, Z. X., Liang, J. H., and Zheng, J. (2010). The role played and opportunities provided by IGP DMC of China National Seismic Network in Wenchuan earthquake disaster relief and researches. Bull. Seismol. Soc. Am., 100(5B), 2866-2872. https://doi.org/10.1785/0120090257 